\title{
COPULATORY BEHAVIOR AND WEB OF INDICOBLEMMA LANNAIANUM FROM THAILAND (ARACHNIDA, ARANEAE, TETRABLEMMIDAE)
}

\author{
Matthias Burger: Natural History Museum, Department of Invertebrates, Bernastrasse \\ 15, CH-3005 Bern, Switzerland. E-mail: burgermatthias@ hotmail.com
}

\author{
Alain Jacob: University of Bern, Department of Conservation Biology, Baltzerstrasse \\ 6, CH-3012 Bern, Switzerland and Natural History Museum, Department of \\ Invertebrates, Bernastrasse 15, CH-3005 Bern, Switzerland.
}

Christian Kropf: Natural History Museum, Department of Invertebrates, Bernastrasse 15, CH-3005 Bern, Switzerland.

\begin{abstract}
The present study reports for the first time on the behavior prior to, during and after the copulation of a member of the haplogyne spider family, Tetrablemmidae and describes the web of this species. Prior to copulation, male and female of Indicoblemma lannaianum from Thailand sometimes avoided each other or the female scared the male away, apparently by vigorous vibrations of her body. When first copulations were initiated, they lasted from 1.21 to $3.8 \mathrm{~h}$ with an average of $2.25 \pm 0.71 \mathrm{~h}(n$ $=17$ ). Some females accepted a second male for mating 3-9 days after first mating. There was no significant difference between the duration of first and second copulations but significantly more trials were needed to induce the second copulations. In the copulatory position, the male was inverted and faced in the same direction as the female. He seized the female's opisthosoma with apophyses on his chelicerae which fit into grooves on a female's ventral plate in this way building a locking mechanism during copulation. The pedipalps were inserted alternately. The web of I. lannaianum consisted of a longish narrow sheet, which was made of many short threads forming a zigzag pattern and additional long oblique threads overdrawing the sheet and functioning as signal threads.
\end{abstract}

Keywords: Haplogynae, copulation, locking mechanism, courtship

Spiders show an impressive array of various copulatory patterns and positions (e. g., Gerhardt 1933; von Helversen 1976; Foelix 1996; Huber \& Eberhard 1997). Although there have been numerous studies on the mating of a variety of spiders, the copulatory behavior of many species still remains unknown. Bristowe and Gerhardt described the mating behavior of several entelegyne species, and of haplogynes including members of the families Scytodidae, Pholcidae, Segestriidae, Dysderidae and Oonopidae (Bristowe 1929-1931; Gerhardt 1926-1930, 1933). In addition to Gerhardt's comprehensive work (reviewed by Huber 1998a), the most detailed descriptions of reproductive biology and copulatory mechanisms in haplogynes are given for the family Pholcidae (Uhl 1993a, 1993b, 1998; Uhl et al. 1995; Huber 1994, 1995, 1997, 1998b, 2002; Huber \& Eberhard 1997; Yoward 1998; Senglet 2001; Schäfer \& Uhl 2002). However, studies on the copulatory behavior of many haplogynes are still missing. This is especially true for members of the family Tetrablemmidae as their behavior has not yet been observed in detail.

Tetrablemmids are armored spiders which mainly live as soil-dwellers in the litter habitat of tropical rain forests (Shear 1978; Lehtinen 1981; Burger 2005). They show a characteristic pattern of abdominal sclerotization, and the carapace or the chelicerae of males are often strongly modified (Shear 1978; Lehtinen 1981; Schwendinger 1989, 1994). The family Tetrablemmidae is systematically placed as sister group of the Dysderoidea (Coddington \& Levi 1991; Platnick et al. 1991).

The diminutive size (body length less than $2 \mathrm{~mm}$ ) of most tetrablemmids and the fact that many species are hard to find make behavioral observations difficult. In the present study we investigate the mating behavior of a tetra- 
blemmid spider and compare the copulation duration of first and second copulations. We also describe avoidance behaviors of males and females, female aggressive behavior prior to copulation, and we provide details of the web of this species.

\section{METHODS}

Specimens of the tetrablemmid Indicoblemma lannaianum Burger 2005 were collected in the primary evergreen hill forest of Doi Suthep, $1600 \mathrm{~m}$ elevation, near Chiang Mai $\left(18^{\circ} 48^{\prime} \mathrm{N}, 98^{\circ} 59^{\prime} \mathrm{E}\right)$ in northern Thailand, from 11-21 July 2003 by sieving. Types are deposited in the Geneva Natural History Museum, Switzerland and the Natural History Museum of Bern, Switzerland. Indicoblemma lannaianum inhabits the middle humid leaf litter layer alongside little streams. Sixty-four females and forty-four males were caught and kept singly in little snap cap glass jars $(3 \mathrm{~cm}$ diameter and $5 \mathrm{~cm}$ height) with ground gypsum, which was moistened every day by one or two drops of water so that the air humidity was almost saturated. The spiders were fed Collembola (Folsomia candida Willem). All spiders were mature when collected and thus their mating history is unknown.

For the mating behavior studies, the spiders were used one or two days after they were collected. Copulations were observed with a binocular microscope (Wild M3; 6.4×, 16×, $40 \times)$ and partially photographed using a digital camera (Canon Power Shot G2). All sixtyfour females and forty-four males were used for the mating observations. For each pairing, the male was carefully removed from his glass jar with a paint-brush and placed into the female's jar. The spiders were left together for 30-60 min. If no copulation was initiated during that time, the male was put back in his own glass jar and another male was offered to the female after a recovery period of $30 \mathrm{~min}$. The first palpal insertion by the male was taken as the beginning of copulation. The end of copulation was defined as the moment when the spiders physically separated. Post-copulatory behavior was observed for 15 minutes in each case.

Eleven females which had copulated once were given the opportunity to mate a second time. One day after a female had copulated in the lab for the first time, different males were offered to her one after another (1-3 males per day). When a female copulated for the second time no more males were offered. If a female did not accept a second male within 14 days, the procedure was stopped and the female was considered as single mated.

Only the six females that had mated twice were included in the statistical comparison of first and second copulations. To compare first and second copulations, two-tailed Wilcoxon Sign-Rank-tests for paired data were applied. We tested for a difference in copulation duration and for a difference in the number of trials needed until successful first and second copulations took place. We used nonparametric statistics because most of our groups to test differed significantly from a normal distribution [duration of second copulations (Shapiro Wilk W-test; $\mathrm{W}=0.775621, P<0.0351)$; number of trials for the first (W $=0.639893$, $P<0.0014)$ and second copulations ( $\mathrm{W}=$ $0.763674, P<0.0270)]$. Averages are given \pm standard deviation.

\section{RESULTS}

Pre-copulatory behavior.-When a male (Figs. 1, 2) was placed in the female's jar (Figs. 3, 4), both spiders usually walked around and appeared to meet each other accidentally. A male who came into contact with the threads of a female's web appeared to commence searching for the female. The female then reacted by turning towards him. No male was ever seen filling his pedipalps with sperm prior to copulation. Sometimes males and females stood immobile at a distance of about 3-5 $\mathrm{mm}$ facing each other for 8-10 minutes before contacting (Fig. 5). When the spiders met frontally, the male either grasped the female directly and took the copulatory position (Figs. 6-10) or he pushed her back and upwards with his front legs. In the latter case both of them palpated each other with their front legs for a few seconds before the male took the copulatory position by going backwards along the ventrum of the female (Fig. 11). When the male approached the female from the side or from behind he jumped at her and gripped her back with his chelicerae. If the female kept running around, the male grasped her opisthosoma with his legs (Fig. 12). Before mating, the male crept under her from the side and took the copulatory position (Figs. 6-10).

Locking mechanism.-When the male was 

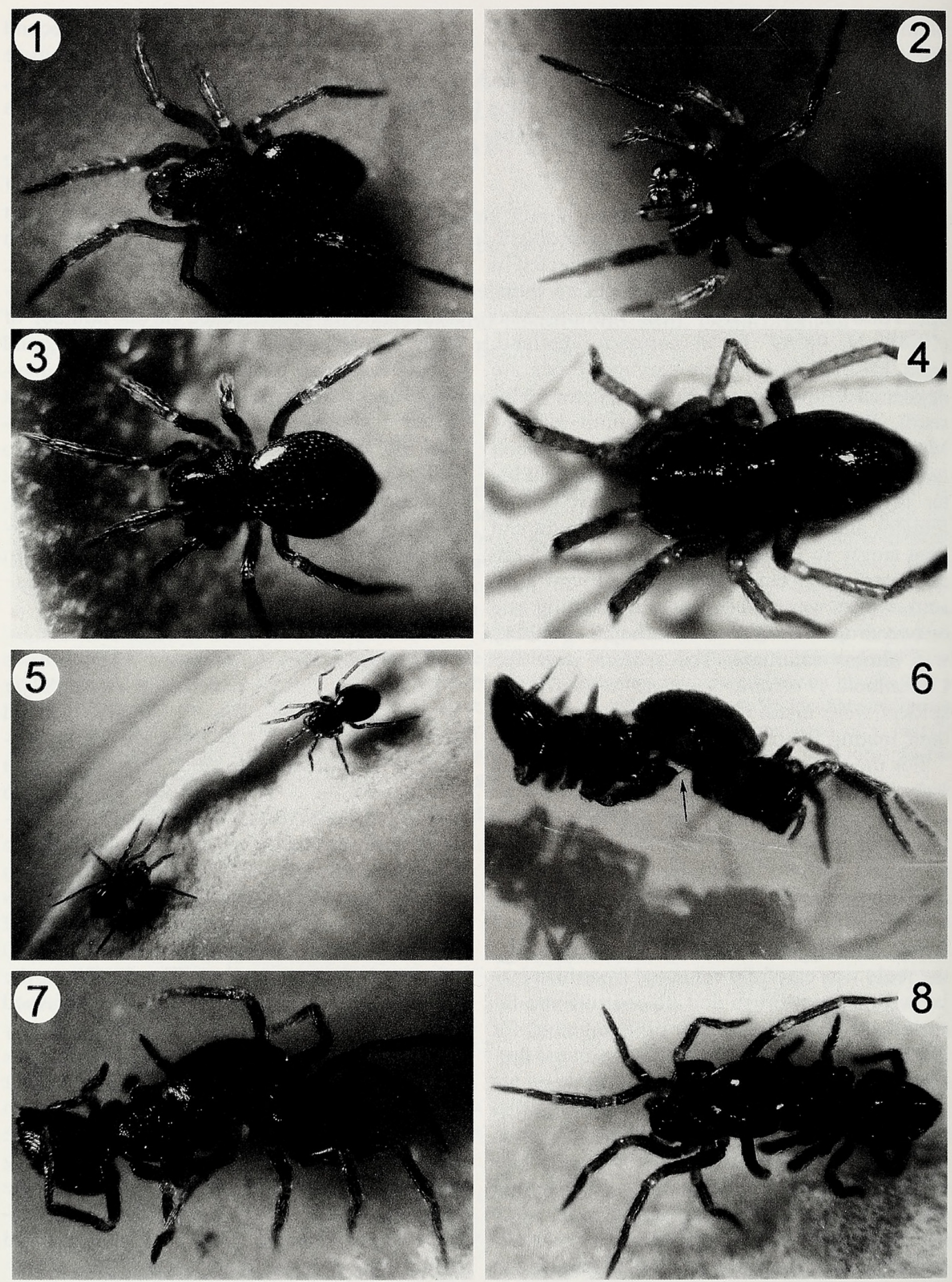

Figures 1-8.-Indicoblemma lannaianum, male and female. 1. Male, dorsal view; 2. Male in web, anterior dorsal view, arrow pointing to signal thread; 3, 4. Female, dorsal view; 5. Male (left side) facing the female prior to copulation; 6. Male (left side) and female in copula, arrow pointing to embolus of male pedipalp; 7. Male (left side) and female in copula; 8. Male (right side) and female in copula. 

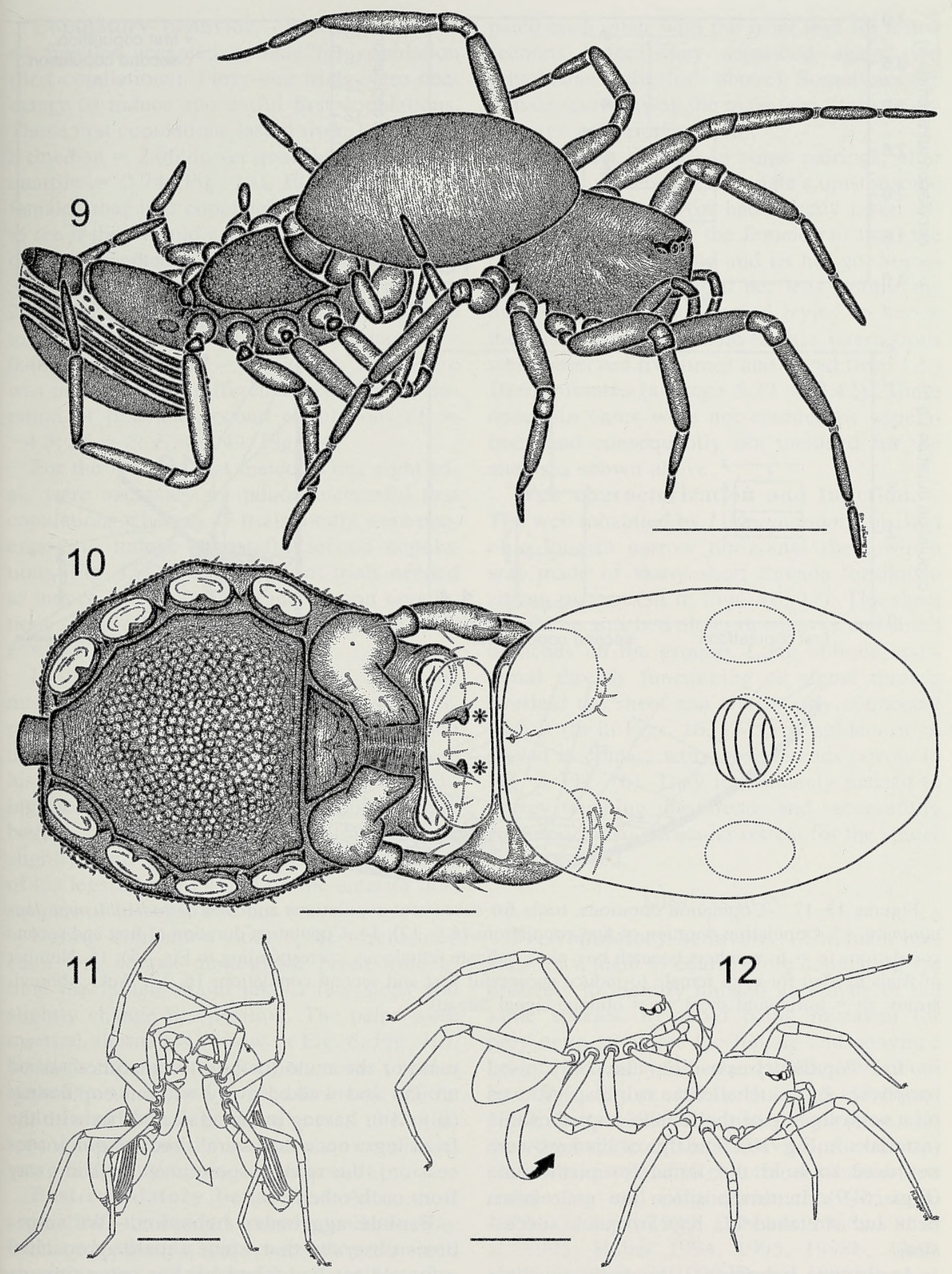

Figures 9-12.-Indicoblemma lannaianum prior and during copulation. 9. Male (left side) and female in copula; 10. Male (prosoma on the left side, ventral view) grasping the female (ventral plates in optical cut, dorsal view) with apophyses on his chelicerae during copulation (asterisks); 11. Male (left side) and female palpating each other with the front legs prior to copulation before the male moves into the copulatory position (arrow); 12. Male (left side) grasping the female's opisthosoma prior to copulation before creeping under her (arrow) and taking the copulatory position. Scale bars $=0.5 \mathrm{~mm}(9,11,12), 0.2 \mathrm{~mm}$ (10). 

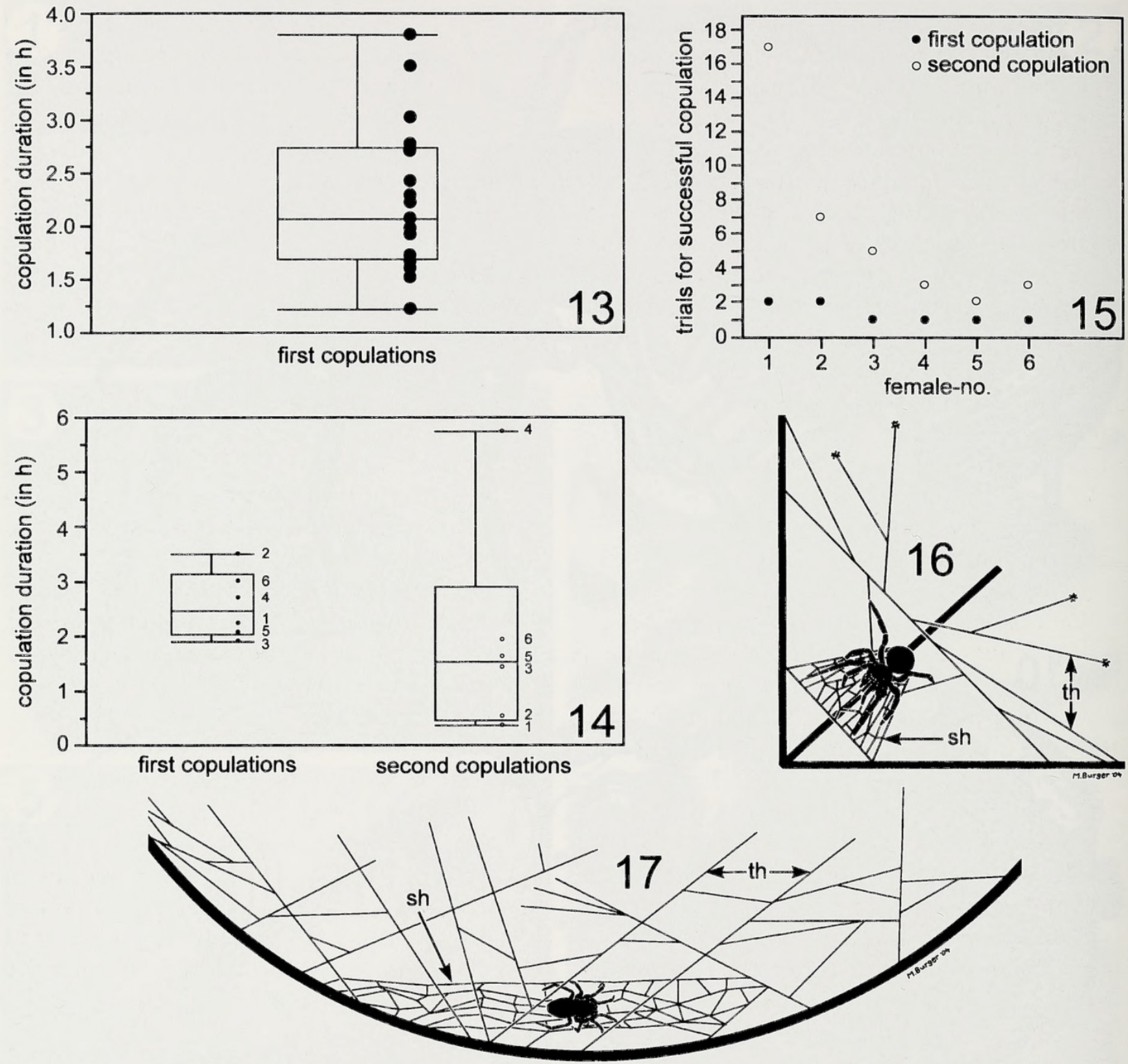

Figures 13-17.-Copulation durations, trials for successful copulations and web of Indicoblemma lannaianum. 13. Copulation duration of first copulations $(n=17) ; 14$. Copulation duration of first and second copulations ( $n=6$; numbers beneath box-plots indicate female-no. corresponding to Fig. 15); 15 . Number of trials needed for each female to induce successful first and second copulation; 16, 17. Web. Abbreviations: $s h=$ horizontal sheet, th $=$ oblique signal threads.

in the copulatory position, he only used apophyses on his chelicerae to grasp grooves on a ventral plate of the female's opisthosoma (asterisks in Fig. 10). The tips of his legs were not used to hold the female's opisthosoma (Figs. 6-9). In this position the male often bent and stretched his legs in quick succession.

Avoidance behavior.-We observed three types of behavior that appeared to be avoidance behavior: (i) Sometimes, when put together, the two spiders ran quickly in different directions. (ii) After facing each other and staying motionless for several minutes, the fe- male or the male (or both) sometimes turned around and walked away without copulating. (iii) After having palpated each other with the front legs (once or several times in quick succession), the spiders sometimes walked away from each other.

Female aggressive behavior.-We sometimes observed that when a male approached a female (or had faced her for some time or had already come into contact with her) she seemed to scare him away by vigorous vibrations of her body, especially the front legs. Such apparent female aggressive behavior was observed 18 times. 
Copulatory behavior.-Seventeen out of 64 females accepted a male for copulation (first copulations). Forty-one trials were necessary to induce successful first copulations. Those first copulations lasted from 1.21 to 3.8 $\mathrm{h}$ (median $=2.06 ;$ lower quartile $=1.7$; upper quartile $=2.74$; Fig. 13). Eleven of the 17 females that had copulated once were tested to see if they would accept a second mate. Six of them accepted a second male for copulation 3-9 days after first copulation (average $4.3 \pm$ 2.3). The second copulations lasted from 0.36 to $5.75 \mathrm{~h}$ (median $=1.53$; lower quartile $=$ 0.48 ; upper quartile $=2.89$; Fig. 14). There was no significant difference between the duration of first and second copulations $(\mathrm{T}=$ -4.5 ; df $=5 ; P<0.44$; Fig. 14).

For the females that mated twice, eight trials were necessary to induce successful first copulations whereas 37 trials totally were necessary to induce successful second copulations (Fig. 15). The numbers of trials needed to induce successful first and second copulations significantly differed $(\mathrm{T}=10.5 ; \mathrm{df}=5$; $P<0.031$; Fig. 15).

In the copulatory position (Figs. 6-10) the male was inverted and faced in the same direction as the female. His legs did not touch the female's opisthosoma. The male only used his chelicerae to grasp the female (see "locking mechanism" above). After copulation had begun, all his legs stayed motionless and slightly bent. The male rested on the patellae of his legs III and IV and on the anterior dorsal part of his opisthosoma.

During copulation both spiders remained calm and almost motionless. From time to time the female could take a few steps and slightly change her position. The palps were inserted alternately (arrow in Fig. 6, Fig. 10). Towards the end of copulation, some females started to run around or tried to knock off the male using their legs. In all cases, the male sprang away from the female when copulation was finished by turning a somersault.

Post-copulatory behavior.--After their separation, the spiders mostly walked away from each other. In some cases, they remained close together and showed intense self-grooming. The male often ran his pedipalps through his chelicerae. When the spiders met a second time by walking around after copulation, they either both ran quickly in different directions and kept out of each other's way, or they pal- pated each other with the front legs for a few seconds before they separated again (see "avoidance behavior" above). Sometimes the female scared away the male (see "female aggressive behavior" above).

Uncertain cases.- In some pairings, after the male had seized the female's opisthosoma with his chelicerae (or had already taken the copulatory position), the female ran until the male loosened his hold and let her go. Sometimes the female pushed her legs against the male's legs and she seemed trying to knock the male off. Such male-female interactions were observed five times and lasted from 1.510.62 minutes (average $5.33 \pm 3.42$ ). These uncertain cases were not counted as copulations and consequently not included for the analyses shown above.

Web characterization and function.The web inhabited by I. lannaianum consisted of a longish narrow horizontal sheet which was made of many short threads forming a zigzag pattern (sh in Figs. 16, 17). The sheet should be attached along dry leaves and small branches on the ground. Long oblique additional threads functioning as signal threads overlaid the sheet and were partly connected with it (th in Figs. 16, 17). The spiders often stayed in contact with these threads (arrow in Fig. 2, Fig. 16). They immediately reacted to a prey touching the threads and successfully captured it. No particular retreat for the spider was observed.

\section{DISCUSSION}

Pre-copulatory behavior.- The main reasons for a male to court before copulation are probably to identify himself as a mate of the same species, to avoid being mistaken for prey or to stimulate the female and convince her of his quality (Eberhard 1985, 1996; Foelix 1996; Huber 1997; Huber \& Eberhard 1997; Bartos 1998). In many haplogyne spiders the male courtship behavior prior to copulation is restricted to abdominal vibrations or simple leg and palp movements (Bristowe 1929; Gerhardt 1929; Dabelow 1958; Uhl et al. 1995; Huber 1994, 1995, 1998b, 2002; Huber \& Eberhard 1997; Bartos 1998; Senglet 2001). In pholcids, males often keep on moving their pedipalps during copulation (copulatory courtship) (Gerhard 1927; Uhl et al. 1995; Huber 1994, 1995, 1998b, 2002; Huber \& Eberhard 1997; Schäfer \& Uhl 2002). Other 
forms of male courtship behavior are tapping or jerking the female's web (Bartos 1998), cutting threads of the female's web (Uhl et al. 1995; Bartos 1998; Senglet 2001), or spreading the chelicerae (Jackson \& Pollard 1982). In exceptional cases male pholcids even perform gustatorial courtship (Huber 1997).

Males of I. lannaianum showed several behaviors that could have some sort of pre-copulatory courtship function. Some males palpated the female and pushed her backwards or the male bent and stretched his legs in quick succession before copulation started. The grasping of the female's opisthosoma by cheliceral apophyses could also have a courtship function (Huber 1999). In 5\% of the cases, distinctive female aggressive behavior was observed: the male may have been ready to copulate, but the female prevented any further interaction by scaring him away. This behavior is a striking indication for pre-copulatory female choice as those females often mated with other males afterwards. Similar female aggressive behavior in haplogynes was observed in certain pholcids prior to copulation (Huber 1994, 1995; Huber \& Eberhard 1997; Bartos 1998) or after copulation (Bartos 1998; Senglet 2001). The fact, that significantly more trials were needed for successful copulation if females had already mated (Fig. 15) could indicate that females become choosier with increasing copulation number as suggested by Schäfer \& Uhl (2002) for Pholcus phalangioides Fuesslin, 1775. Nevertheless copulations also seemed to take place without pronounced pre-copulatory courtship as sometimes males just grasped the females forcefully with their chelicerae and took the copulatory position directly.

Locking mechanism.-A cheliceral locking mechanism (by apophyses or modified cheliceral hairs) during copulation in haplogyes was reported for certain scytodids (Dabelow 1958) and pholcids (Huber 1994, 1995, 1998b, 2002; Uhl et al. 1995; Senglet 2001). Lehtinen (1981) proposed that some tetrablemmids use apophyses on their chelicerae to grasp corresponding grooves on a ventral plate of the female during copulation. The present study confirms this suggestion for the first time by live observations.

Copulation duration.-Copulation duration is quite variable among different spiders. Elgar (1995) suggested that haplogynes have shorter copulations because of the simplicity of their copulatory apparatus. However, studies have shown that the copulatory organs of some haplogynes are in fact quite complex (e. g., Uhl 2000; Burger et al. 2003), and little is known about the copulation duration of many haplogynes. A few of the haplogyne spiders investigated so far copulate longer than one hour (Gerhardt 1927-1929, 1933; Uhl 1993a; Bartos 1998; Senglet 2001; Schäfer \& Uhl 2002). The longest copulation known for a haplogyne spider was longer than 5 hours in the oonopid Silhouettella loricatula (Roewer 1942) (sub Dysderina loricata) (Bristowe 1930).

It seems obvious that the function of a prolonged copulation in general cannot be explained by prolonged sperm transfer only (Eberhard 1985; Suter \& Parkhill 1990). During long copulations, apparent risks are accepted, which should favor brief mating (e. g. increased danger from predators or interruption by another male or by the female before sperm transfer is completed; Eberhard 1996). Copulation duration may correlate with the amount of transferred sperm (Engqvist \& Sauer 2003) and/or with fertilization success (Andres \& Rivera 2000) but Schäfer \& Uhl (2002) showed that longer copulations do not indicate higher fertilization rates in their study. The prolonged copulation duration in $I$. lannaianum could be explained by sperm competition hypotheses such as sperm precedence (Suter \& Parkhill 1990; Elgar 1998) and/or by hypotheses of sexual selection by cryptic female choice (the male could initiate processes in the female during copulation which increase his chances of siring her offspring; Eberhard 1985, 1996). The prolonged copulation could also serve as mate guarding. By guarding the female, a male can restrict access to females from other males (SillénTullberg 1981; Wynn \& Vahed 2004) and consequently guard and protect his own transferred ejaculate (Schöfl \& Taborsky 2002). These are all hypotheses yet to be tested but it appears that $I$. lannaianum could be a good species for testing these ideas.

The second copulation of female no. 4 (Fig. 14) seemed to last disproportionately long when compared to the other second copulations. Excluding it from the analysis would result in a trend towards a decreased duration of the second copulations. Schäfer \& Uhl 
(2002) suggested that shorter second copulations resulted from a stronger conflict of interest between the sexes over paternity in second matings.

Copulatory position.-The evolution of the mating positions in spiders was discussed by von Helversen (1976). The most plesiomorphic copulatory position is the one taken by most mygalomorphs and haplogynes like Oonops (Gerhardt 1930), Segestria or Filistata (Gerhardt 1928, 1929): the male approaches the female frontally, pushes her body back and upwards and inserts his pedipalps simultaneously or alternately (von Helversen 1976). Among different spider groups, a change from the plesiomorphic to a derived copulatory position took place convergently: the male rests on the ventral side of the female and both partners face in the same direction. This position is seen in the oonopids Silhouettella (Bristowe 1930) and Xestaspis (Gerhardt 1933).

Indicoblemma lannaianum takes the derived copulatory position. The behavior before some copulations could be a remnant of the one shown by spiders that take the plesiomorphic position: the male pushes the female back and they palpate each other with the front legs for a few seconds (Fig. 11) before he goes backwards along the ventrum of the female and takes the derived copulatory position (Figs. 6-10).

\section{Web characterization and function.--} The web of $I$. lannaianum resembles the only web known so far of a tetrablemmine spider. In Brignoliella vulgaris Lehtinen 1981, it is a small dense sheet attached along the surface of large dry leaves (Lehtinen 1981). Schwendinger (1989) described the web constructed by Perania nasuta Schwendinger 1989, a member of the subfamily Pacullinae. It is a loose sheetweb in which the spider hangs upside down at night.

\section{ACKNOWLEDGMENTS}

We are most grateful to Dr. Peter Schwendinger from the Geneva Natural History $\mathrm{Mu}$ seum, who discovered the species and gave us important information about the type locality in Thailand. The trip to Thailand was financed by a travel grant of the Swiss Academy of Sciences (SAS) which is greatly acknowledged. We sincerely thank Prof. Dr. Claus Wedekind for helpful comments on the manu- script. A.J. thanks the Natural History Museum of Bern and the Swiss National Science Foundation for financial support.

\section{LITERATURE CITED}

Andres, J.A. \& A.C. Rivera. 2000. Copulation duration and fertilization success in a damselfly: an example of cryptic female choice? Animal Behaviour 59:695-703.

Bartos, M. 1998. Quantitative analyses of male courtship behaviour in Pholcus phalangioides (Fuesslin, 1775) (Araneae, Pholcidae). In: Selden P.A., editor. Proceedings of the $17^{\text {th }}$ European Colloquium of Arachnology, Edinburgh 1997. British Arachnological Society, Burnham Beeches. p 171-176.

Bristowe, W.S. 1929. The mating habits of spiders, with special reference to the problems surrounding sex dimorphism. Proceedings of the Zoological Society of London 1929:309-358.

Bristowe, W.S. 1930. A supplementary note on the mating habits of spiders. Proceedings of the Zoological Society of London 1930:395-413.

Bristowe, W.S. 1931. The mating habits of spiders: a second supplement, with the description of a new thomisid from Krakatau. Proceedings of the Zoological Society of London 1931:1401-1412.

Burger, M. 2005. The spider genus Indicoblemma Bourne with description of a new species (Araneae: Tetrablemmidae). Bulletin of the British Arachnological Society 13:97-111.

Burger, M., W. Nentwig \& C. Kropf. 2003. Complex genital structures indicate cryptic female choice in a haplogyne spider (Arachnida, Araneae, Oonopidae, Gamasomorphinae). Journal of Morphology 255:80-93.

Coddington, J.A. \& H.W. Levi. 1991. Systematics and evolution of spiders (Araneae). Annual Review of Ecology and Systematics 22:565-592.

Dabelow, S. 1958. Zur Biologie der Leimschleuderspinne Scytodes thoracica (Latreille). Zoologische Jahrbücher Systematik 86:85-126.

Eberhard, W.G. 1985. Sexual selection and animal genitalia. Harvard University Press, Cambridge, Massachusetts.

Eberhard, W.G. 1996. Sexual selection by cryptic female choice. Princeton University Press, Princeton, New Jersey.

Elgar, M.A. 1995. The duration of copulation in spiders: comparative patterns. Records of the Western Australian Museum 52:1-11.

Elgar, M.A. 1998. Sperm competition and sexual selection in spiders and other arachnids. Pp. 307-339. In Birkhead, T.R. \& A.P. Møller, editors. Sperm Competition and Sexual Selection. London, Academic Press.

Engqvist, L. \& K.P. Sauer. 2003. Determinants of sperm transfer in the scorpionfly Panorpa cognata: male variation, female condition and cop- 
ulation duration. Journal of Evolutionary Biology $16: 1196-1204$.

Foelix, R.F. 1996. Biology of Spiders. Second edition. Oxford University Press, Oxford.

Gerhardt, U. 1926. Weitere Untersuchungen zur Biologie der Spinnen. Zeitschrift für Morphologie und Ökologie der Tiere 6:1-77.

Gerhardt, U. 1927. Neue biologische Untersuchungen an einheimischen und ausländischen Spinnen. Zeitschrift für Morphologie und Ökologie der Tiere 8:96-186.

Gerhardt, U. 1928. Biologische Studien an griechischen, corsischen und deutschen Spinnen. Zeitschrift für Morphologie und Ökologie der Tiere 10:576-675.

Gerhardt, U. 1929. Zur vergleichenden Sexualbiologie primitiver Spinnen, insbesondere der Tetrapneumonen. Zeitschrift für Morphologie und Ökologie der Tiere 14:699-764.

Gerhardt, U. 1930. Biologische Untersuchungen an südfranzösischen Spinnen. Zeitschrift für Morphologie und Ökologie der Tiere 19:184-227.

Gerhardt, U. 1933. Neue Untersuchungen zur Sexualbiologie der Spinnen, insbesondere an Arten der Mittelmeerländer und der Tropen. Zeitschrift für Morphologie und Ökologie der Tiere 27:175.

Huber, B.A. 1994. Genital morphology, copulatory mechanism and reproductive biology in Psilochorus simoni (Berland, 1911) (Pholcidae; Araneae). Netherlands Journal of Zoology 44:85-99.

Huber, B.A. 1995. Copulatory mechanism in Holocnemus pluchei and Pholcus opilionoides, with notes on male cheliceral apophyses and stridulatory organs in Pholcidae (Araneae). Acta Zoologica Stockholm 76:291-300.

Huber, B.A. 1997. Evidence for gustatorial courtship in a haplogyne spider (Hedypsilus culicinus: Pholcidae: Araneae). Netherlands Journal of Zoology 47:95-98.

Huber, B.A. 1998a. Spider reproductive behavior: a review of Gerhardt's work from 1911-1933, with implications for sexual selection. Bulletin of the British Arachnological Society 11:81-91.

Huber, B.A. 1998b. Genital mechanics in some neotropical pholcid spiders (Araneae: Pholcidae), with implications for systematics. Journal of Zoology London 244:587-599.

Huber, B.A. 1999. Sexual selection in pholcid spiders (Araneae, Pholcidae): artful chelicerae and forceful genitalia. Journal of Arachnology 27: 135-141.

Huber, B.A. 2002. Functional morphology of the genitalia in the spider Spermophora senoculata (Pholcida, Araneae). Zoologischer Anzeiger 241: 105-116.

Huber, B.A. \& W.G. Eberhard. 1997. Courtship, copulation, and genital mechanics in Physocyclus globosus (Araneae, Pholcidae). Canadian Journal of Zoology 74:905-918.

Jackson, R.R. \& S.D. Pollard. 1982. The biology of Dysdera crocata (Araneae, Dysderidae): Intraspecific interactions. Journal of Zoology London 198:197-214.

Lehtinen, P.T. 1981. Spiders of the Oriental-Australian region. III. Tetrablemmidae, with a world revision. Acta Zoologica Fennica 162:1-151.

Platnick, N.I., J.A. Coddington, R.R. Forster \& C.E. Griswold. 1991. Spinneret morphology and the phylogeny of haplogyne spiders (Araneae, Araneomorphae). American Museum Novitates 3016:1-73.

Schäfer, M.A. \& G. Uhl. 2002. Determinants of paternity success in the spider Pholcus phalangioides (Pholcidae: Araneae): the role of male and female mating behaviour. Behavioral Ecology and Sociobiology 51:368-377.

Schöfl, G. \& M. Taborsky. 2002. Prolonged tandem formation in firebugs (Pyrrhocoris apterus) serves mate-guarding. Behavioral Ecology and Sociobiology 52:426-433.

Schwendinger, P.J. 1989. On three new armoured spiders (Araneae: Tetrablemmidae, Pacullinae) from Indonesia and Thailand. Revue Suisse de Zoologie 96:571-582.

Schwendinger, P.J. 1994. Four new Perania (Araneae: Tetrablemmidae, Pacullinae) from Thailand and Malaysia. Revue Suisse de Zoologie 101: 447-464.

Senglet, A. 2001. Copulatory mechanisms in Hoplopholcus, Stygopholcus (revalidated), Pholcus, Spermophora and Spermophorides (Araneae, Pholcidae), with additional faunistic and taxonomic data. Mitteilungen der Schweizerischen Entomologischen Gesellschaft 74:43-67.

Shear, W.A. 1978. Taxonomic notes on the armored spiders of the families Tetrablemmidae and $\mathrm{Pa}$ cullidae. American Museum Novitates 2650:146.

Sillén-Tullberg, B. 1981. Prolonged copulation: a male "postcopulatory" strategy in a promiscuous species, Lygaeus equestris (Heteroptera: Lygaeidae). Behavioral Ecology and Sociobiology 9:283-289

Suter, R.B. \& V.S. Parkhill 1990. Fitness consequences of prolonged copulation in the bowl and doily spider. Behavioral Ecology and Sociobiology 26:369-373.

Uhl, G. 1993a. Mating behaviour and female sperm storage in Pholcus phalangioides (Fuesslin) (Araneae). Memoirs of the Queensland Museum 33: 667-674.

Uhl, G. 1993b. Sperm storage and repeated egg production in female Pholcus phalangioides Fuesslin (Araneae). Bulletin de la Société Neuchâteloise des Sciences Naturelles 116:245-252.

Uhl, G. 1998. Mating behavior in the cellar spider, 
Pholcus phalangioides, indicates sperm mixing. Animal Behavior 56:1155-1159.

Uhl, G. 2000. Two distinctly different sperm storage organs in female Dysdera erythrina (Araneae: Dysderidae). Arthropod Structure \& Development 29:163-169.

Uhl, G., B.A. Huber \& W. Rose. 1995. Male pedipalp morphology and copulatory mechanism in Pholcus phalangioides (Fuesslin, 1775) (Araneae, Pholcidae). Bulletin of the British Arachnological Society 10:1-9.

von Helversen, O. 1976. Gedanken zur Evolution der Paarungsstellung bei den Spinnen (Arachnida: Araneae). Entomologica germanica 3:13-28.
Wynn, H. \& K. Vahed. 2004. Male Gryllus bimaculatus guard females to delay them from mating with rival males and to obtain repeated copulations. Journal of Insect Behavior 17:53-66.

Yoward, P.J. 1998. Sperm competition in Pholcus phalangioides (Fuesslin, 1775) (Araneae, Pholcidae) - shorter copulations gain higher paternity reward than first copulations. In: Selden P.A., editor. Proceedings of the $17^{\text {th }}$ European Colloquium of Arachnology, Edinburgh 1997. British Arachnological Society, Burnham Beeches. p 167-170.

Manuscript received 27 August 2004, revised 23 February 2005. 


\section{$2 \mathrm{BHL}$ Biodiversity Heritage Library}

Burger, Matthias, Jacob, Alain, and Kropf, Christian. 2006. "COPULATORY BEHAVIOR AND WEB OF INDICOBLEMMA LANNAIANUM FROM THAILAND (ARACHNIDA, ARANEAE, TETRABLEMMIDAE)." The Journal of arachnology 34(1), 176-185. https://doi.org/10.1636/s04-60.1.

View This Item Online: https://www.biodiversitylibrary.org/item/222923

DOI: https://doi.org/10.1636/s04-60.1

Permalink: https://www.biodiversitylibrary.org/partpdf/228920

\section{Holding Institution}

Smithsonian Libraries

\section{Sponsored by}

Biodiversity Heritage Library

\section{Copyright \& Reuse}

Copyright Status: In Copyright. Digitized with the permission of the rights holder

Rights Holder: American Arachnological Society

License: https://creativecommons.org/licenses/by-nc-sa/4.0/

Rights: https://www.biodiversitylibrary.org/permissions/

This document was created from content at the Biodiversity Heritage Library, the world's largest open access digital library for biodiversity literature and archives. Visit BHL at https://www.biodiversitylibrary.org. 